\section{Knowledge regarding HIV/AIDS among home-based caregivers in Namibia}

\author{
Hileni Niikondo, ${ }^{1}$ Muhammad Hoque, ${ }^{2}$ \\ Busi Ntuli-Ngcobo ${ }^{2}$ \\ 'School of Nursing and Public Health, \\ University of Namibia (Northern \\ Campus), Namibia \\ ${ }^{2}$ School of Health Care Sciences, \\ University of Limpopo (Medunsa \\ Campus), South Africa
}

\section{Abstract}

Lack of practical knowledge among homebased caregivers on human immunodeficiency virus/acquired immune deficiency syndrome (HIV/AIDS), anti-retroviral therapy (ART) and poor individual adherence to treatment are among the root causes of ineffective ART service delivery in Namibia. The purpose of our study was to investigate the knowledge among home-based caregivers in Namibia regarding HIV/AIDS. The study was a descriptive, crosssectional one in which 89 participants completed a self-administered questionnaire to assess their knowledge of HIV/AIDS. Almost all $(93 \%)$ of the respondents gave a correct definition of HIV. Over a tenth (11.3\%) did not know that HIV decreases the body's ability to fight disease and $33.7 \%$ could not define AIDS. Almost all (98\%) the home-based caregivers knew that HIV can be diagnosed only through a blood test and $91 \%$ mentioned that consistent and correct use of condoms during sexual intercourse protects one from HIV infection. Fewer than half (44\%) of the respondents could indicate on-and-off fever as a symptom of AIDS and 16\% mentioned that increased body weight is a sign of AIDS, which is incorrect. Although the knowledge of the caregivers on HIV/AIDS was above average in some aspects, there was still lack of knowledge on isolated issues such as AIDS definitions and signs and how HIV works. Training organisations in home-based care settings should emphasise the knowledge of AIDS definition and signs as well as of post-test counselling, consequence of poor adherence and facilities that issue anti-retroviral treatment.

\section{Introduction}

Sub-Saharan Africa remains the hardest hit by human immunodeficiency virus/acquired immune deficiency syndrome (HIV/AIDS). Over two-thirds (67\%, 22.4 million) of all its people are living with HIV and nearly threequarters (72\%) of AIDS-related deaths occurred in this region in 2008. ${ }^{1}$ In Namibia, an estimated 200,000 people were living with HIV/AIDS with an adult prevalence rate of $15.3 \% .^{1}$ This is an alarming situation that calls for the participation of all healthcare workers, faith-based organisations, civil society counsellors, volunteers, and knowledgeable people at the community level such as home-based caregivers.

Basic knowledge about HIV/AIDS appears to be limited in African countries. For example, in a study from Nigeria, only $15 \%$ of people surveyed were able to describe HIV/AIDS as a deadly disease and $69 \%$ of young women from Burkina Faso were aware that AIDS was deadly. ${ }^{2,3}$ A study from Northern Kenya found that $64 \%$ of women named 'wasting' as a symptom of AIDS. ${ }^{4}$ Many African women incorrectly believe that AIDS can be cured..$^{5-8}$ Most African people are aware now that HIV can be transmitted through unsafe sex. ${ }^{9-11}$ Knowledge about other modes of transmission like unsterilised injecting equipment, blood transfusions, contaminated instruments, and mother-tochild transmission is more variable. ${ }^{12,13}$

The home-based care guidelines in Namibia stipulate comprehensive knowledge requirements for home-based caregivers on HIV/AIDS useful at the community level; that is, the basic information on HIV/AIDS, which includes the definition of HIV as human immuneodeficiency virus. The modes of transmission are clearly stipulated, ranging from unprotected sexual intercourse, transmission through blood transfusions and contaminated instruments such as needles and skin-piercing instruments, as well as transmission from an infected mother to her child. ${ }^{14}$ Home-based caregivers need to be able to differentiate HIV from AIDS. This includes the knowledge about the importance of an HIV test, the meaning of HIV positive and negative results, opportunistic infections, basic nutrition for an HIV/AIDS person, and positive living. ${ }^{15}$

The knowledge and practices of home-based caregivers play a vital role in mobilising communities to access healthcare services for information on HIV/AIDS and treatment. ${ }^{16}$ Lack of practical knowledge among home-based caregivers on HIV/AIDS, anti-retroviral therapy (ART) and poor individual adherence to treatment are among the root causes of ineffective ART service delivery in Namibia. This results in a high defaulter rate and increased HIV/AIDS related morbidity and mortality, which is estimated to be about 16,000 to 32,000 persons on ART. ${ }^{17}$ The devastating epidemic of HIV/AIDS has resulted in an increase in the demand for care. Thus, the purpose of our study was to investigate the knowledge among home-based caregivers in Namibia regarding HIV/AIDS.
Correspondence: Muhammad Hoque, Department of Public Health, School of Health Care Sciences, University of Limpopo (Medunsa Campus), South Africa.

Tel. +27 0125213093 - Fax: +27 0125214607

E-mail: muhammad_hoque@embanet.com

Key words: HIV, AIDS, knowledge, home-based caregiver, Namibia.

Contributions: all authors contributed to the conception and design of the study, drafting and final approval of the article, and HN and MH to analysis and interpretation of data.

Acknowledgements: the authors wish to thank the Lutheran Church board and the management of the Roman Catholic Church for support in conducting the study. No funding was received for the study.

Conflict of interest: the authors report no conflicts of interest.

Received for publication: 3 September 2010. Accepted for publication: 20 January 2011.

This work is licensed under a Creative Commons Attribution 3.0 License (by-nc 3.0).

(O) Copyright H. Niikondo et al., 2011

Licensee PAGEPress, Italy

Journal of Public Health in Africa 2011; 2:e6

doi:10.4081/jphia.2011.e6

\section{Materials and Methods}

\section{Study design and settings}

This was a cross-sectional, descriptive, quantitative study conducted in two faithbased organisations in Windhoek, Namibia; namely: the Evangelical Lutheran Church care programme and Catholic AIDS Action care programme. Both organisations are located in the Katutura area in Windhoek. Windhoek is the capital city of Namibia and is situated in the central part of the country. The population of Windhoek during the time of our study was 243,272 people according to the population census of 2001. Windhoek is divided into five geographical areas and 173,000 people live in the north and north-western areas of Windhoek. These two areas form the largest part of Katutura where this study took place. Most residents in this area have low incomes.

\section{Study population}

The study population consisted of all (89) home-based caregivers working in the two faith-based organisations (67 from Catholic AIDS Action for the Roman Catholic Church and 22 from the Evangelical Lutheran Church care programme in Windhoek). These two organisations were selected randomly but no 
sampling was done as all the 89 home-based caregivers who were working in these institutions were invited to and participated in the study.

\section{Ethical considerations}

Ethical clearance for the study was obtained from the Medunsa Campus Research and Ethics Committee of the University of Limpopo, South Africa (MCREC/PH/112/2007: PG). Permission to conduct the study was obtained from the Lutheran Church board and the management of the Roman Catholic Church. Informed written consent of participants was obtained. Confidentiality of participants was maintained at all times. To further maintain confidentiality, no form of identifier was in the questionnaires. Participation was voluntary and participants were informed that they could withdraw from the study at any stage of the interview if they so desired, without any penalty.

\section{Data collection instrument and data collection}

A structured, closed ended questionnaire was used to collect data. The questionnaire was divided into two sections. The first section was on demographic characteristics and the second section was related to HID/AIDS. Validity control measures were handled through consultation with two experts in the field of research in the Ministry of Health and Social Services, Namibia and the University of Namibia. These experts assisted with the verification that the content of the questionnaire reflected what was to be measured. All questions were clear and understandable in order to avoid any inconvenience during the time of data collection. Ten questionnaires were pretested on home-based caregivers in different organisations, namely AIDS Care Trust and Red Cross Namibia. The outcomes were used in the modification of the tool in order to ensure reliability.

The questionnaires were handed over to the respondents during their yearly report meetings with the home-based care coordinators and were distributed after the meetings in the presence of the researcher. Questionnaires were handed back upon completion at the same time so that they could not share ideas or copy responses from their colleagues. The tool was designed in English because all targeted caregivers were literate in English.

\section{Data analysis}

Data were checked for completion, cleaned and entered into the Microsoft Excel 2003 spreadsheet and imported to SPSS 17.0.1 for Windows version for analysis. The results of participants' demographics and baseline out- come variables were summarised using descriptive summary measures, expressed as the mean (standard deviation, SD) for continuous variables and a percentage for categorical variables.

\section{Results}

Table 1 shows the socio-demographic information of the respondents. More than threequarters $(75.3 \%)$ were females, the majority (79.8\%) were below the age of 40 years and most caregivers (66.7\%) had received secondary education. The majority $(86.5 \%)$ had received training as home-based caregivers and among them fewer than half (48\%) received weeks of training. More than half the caregivers (62.7\%) had little experience in the home-based care service. Refresher courses covered a period of $5-10$ years as indicated by the majority of caregivers (69.0\%). Almost half of the caregivers (48.3\%) belonged to the Lutheran religious faith.

\section{Knowledge on HIV/AIDS}

Table 2 shows the home-based caregivers' knowledge regarding HIV/AIDS. Almost all (93\%) of the respondents gave a correct definition of HIV whereas all respondents knew how HIV is transmitted. More than a tenth (11.3\%) did not know that HIV decreases the body's ability to fight disease and more than a third (33.7\%) could not define AIDS. Almost all the home-based caregivers knew that HIV can be diagnosed only through a blood test (98\%) and

Table 2. Home-based caregiver's knowledge on HIV/AIDS.

\begin{tabular}{|c|c|c|c|c|}
\hline \multirow[t]{2}{*}{ Statements } & \multicolumn{2}{|c|}{ Trained } & \multirow{2}{*}{$\begin{array}{c}\text { Total } \\
(\mathrm{n}=89)\end{array}$} & \multirow[t]{2}{*}{$\%$} \\
\hline & $\begin{array}{l}\text { Yes } \\
(\mathrm{n}=77)\end{array}$ & $\begin{array}{l}\text { No } \\
(\mathrm{n}=12)\end{array}$ & & \\
\hline Knew correct definition of HIV & 73 & 10 & 83 & 93 \\
\hline Knew correct mode of HIV transmission & 77 & 12 & 89 & 100 \\
\hline HIV decreases the body's ability to fight disease & 62 & 8 & 70 & 78.7 \\
\hline Knew the definition of AIDS & 52 & 7 & 59 & 66.3 \\
\hline $\begin{array}{l}\text { An HIV positive person means he/ } \\
\text { she is infected with the HIV virus }\end{array}$ & 70 & 10 & 80 & 89.9 \\
\hline $\begin{array}{l}\text { AIDS makes the immune system weak and } \\
\text { more susceptible to infections }\end{array}$ & 65 & 12 & 77 & 86.5 \\
\hline $\begin{array}{l}\text { One can only get HIV diagnosed through } \\
\text { HIV blood test }\end{array}$ & 75 & 12 & 87 & 98 \\
\hline $\begin{array}{l}\text { Consistent and correct use of condoms during } \\
\text { sexual intercourse protects one from HIV infection }\end{array}$ & 69 & 12 & 81 & 91 \\
\hline \multicolumn{5}{|l|}{ Knowledge on AIDS signs } \\
\hline On-and-off fever is an AIDS symptom & 30 & 9 & 39 & 44 \\
\hline On-and-off diarrhoea for a few days is a sign of AIDS & 22 & 9 & 31 & 35 \\
\hline Loss of body weight is a sign of AIDS & 16 & 5 & 21 & 24 \\
\hline Increased body weight is a sign of AIDS & 12 & 2 & 14 & 16 \\
\hline
\end{tabular}

Table 1. Socio-demographic information of the participants $(n=89)$.

\begin{tabular}{lcc} 
Variables & n & $\%$ \\
Sex & & \\
Female & 67 & 75.3 \\
Male & 22 & 24.7 \\
Age group & & \\
20-30 yr & 28 & 31.5 \\
$31-40$ yr & 43 & 48.3 \\
$41-50$ yr & 11 & 12.4 \\
50+ yr & 7 & 7.9 \\
\hline Educational level & & \\
Primary & 20 & 23.0 \\
Secondary & 58 & 66.7 \\
Tertiary & 9 & 10.3 \\
Trained & & \\
Yes & 77 & 86.5 \\
No & 12 & 13.5 \\
Duration & & \\
Weeks & 37 & 48.1 \\
Months & 30 & 39.0 \\
Years & 10 & 12.9 \\
\hline Experience & & \\
0-5 yr & 52 & 62.7 \\
5-10 yr & 26 & 31.3 \\
10-15 yr & 4 & 4.8 \\
15+ yr & 1 & 1.2 \\
Refresher course & & \\
1-5 yr & 20 & 23.8 \\
5-10 yr & 58 & 69.0 \\
10-15 yr & 5 & 6.0 \\
15+ yr & 1 & 1.2 \\
\hline Religion & & \\
Lutheran & 43 & 48.3 \\
Catholic & 26 & 29.2 \\
Other & 20 & 22.5 \\
\hline & & \\
\hline
\end{tabular}


91\% mentioned that consistent and correct use of condoms during sexual intercourse protects one from HIV infection. Knowledge regarding symptoms of AIDS was poor among the homebased caregivers. Fewer than half $(44 \%)$ of the respondents could indicate on-and-off fever as a symptom of AIDS and more than a third (35\%) could indicate on-and-off diarrhoea for a few days as a sign of AIDS. Sixteen per cent incorrectly mentioned that increased body weight is a sign of AIDS. Overall, the know ledge regarding HIV/AIDS was similar between trained and non-trained home-based caregivers.

\section{Discussion}

Our study was conducted to investigate the knowledge regarding HIV/AIDS among homebased caregivers in Namibia. We found that the majority of home-based caregivers had knowledge of what HIV stands for but it is still of concern that some caregivers could not define HIV. It is expected that they know about HIV in order to provide information, education about HIV and to differentiate between HIV and AIDS.

All the caregivers knew how HIV is transmitted. This finding is similar to that of studies conducted elsewhere. ${ }^{10-12}$ It was therefore very encouraging to learn that people entrusted with HIV/AIDS clients know about this important issue. A similar study done in Uganda concluded that people with correct information on HIV transmission help in the reduction of misconception, myths, blame and discrimination. ${ }^{18}$

Most caregivers had the knowledge that HIV decreases the ability to fight infections in the body. It was good to note that with this information caregivers may be able to help improve clients' health and facilitate access to ART, if the client's CD4 drops down to 300 counts. Twenty-two per cent of those who lack knowledge of these issues create worry and concern because they may not be able to support and advise patients to go for ART treatment.

The majority (89.9\%) knew what HIV means and this led the researcher to conclude that with this knowledge, home-based caregivers may be able to reduce stigma and discrimination against HIV positive people in the community. As indicated by the results, most caregivers knew the method of determining HIV status. About $98 \%$ indicated that HIV status can only be known after an HIV blood test. Voluntary counselling and testing is an import ant component of HIV and AIDS management. It is believed that this knowledge may help them encourage people to go for voluntary counselling and testing, as confirmed by a study done in Ethiopia, which concluded that home-based caregivers facilitate counselling and treatment preparedness. ${ }^{19}$

Although the majority of caregivers indicated knowledge on the signs and symptoms presented by a person with AIDS, it is still of concern that some of them did not know all the signs of AIDS as $16 \%$ incorrectly mentioned that increased body weight is a sign of AIDS. This is similar to a study conducted among African women. ${ }^{2,3}$ Home-based caregivers need to identify the symptoms associated with AIDS to be able to give correct advice to HIV clients and to assist them through counselling to make use of health facilities for possible ART treatment. Condom use is an important strategy for reducing HIV infections and it was good to find out that home-based caregivers had knowledge on the correct way of preventing HIV transmission through constant usage of condoms.

\section{Limitations of the study}

Findings from our study cannot be generalised to the whole population of the homebased caregivers because this study involves only two faith-based organisations. HIV/TB coinfection was not covered because there is an organisation that deals with TB patients in Windhoek, namely Penduka for TB volunteers.

\section{Conclusions}

Although knowledge of caregivers on HIV/AIDS was above average in some aspects, there was still lack of knowledge on isolated issues, such as AIDS definitions and signs and how HIV works. This indicates training deficits among the home-based caregivers. Therefore, refresher courses and workshops are needed to update caregivers with correct information. Training organisations in home-based care settings should evaluate the curriculum of caregivers to ensure that the content is updated with all the information and emphasise the knowledge of AIDS definition and signs as well as of post-test counselling, consequence of poor adherence and facilities that issue ART.

\section{References}

1. UNAIDS. Report on the global AIDS epidemic, 2009. Available from: http://data. unaids.org/pub/FactSheet/2009/20091124_ FS_SSA_en.pdf. (Accessed 15 February 2009).

2. Yahaya MK. Analysis of women's reproductive health situation in Bida Emirate of Niger State, Nigeria. Afr J Reprod Health 2002;6:50-64.
3. Sarker M, Milkowski A, Slanger T, et al. The role of HIV-related knowledge and ethnicity in determining HIV risk perception and willingness to undergo HIV testing among rural women in Burkina Faso. AIDS Behav 2005;9:243-9.

4. Roth EA, Fratkin EM, Ngugi EN, Glickman BW. Female education, adolescent sexuality and the risk of sexually transmitted infection in Ariaal Rendille culture. Culture, Health \& Sexuality 2001;3:35-47.

5. Ibe SN. HIV/AIDS awareness study of fresh students in tertiary institutions in Rivers State of Nigeria Department of Nigeria. J Appl Sci Environ Manag 2005;9:11-13.

6. Cherie A, Mitkie G, Ismail S, Berhane Y. Perceived sufficiency and usefulness of IEC materials and methods related to HIV/AIDS among high school youth in Addis Ababa, Ethiopia. Afr J Reprod Health 2005;9:66-77.

7. Kalichman SC, Simbayi L. HIV testing attitudes, AIDS stigma, and voluntary HIV counselling and testing in a black township in Cape Town, South Africa. Sex Transm Infect 2003;79:442-7.

8. Simbayi LC, Kalichman SC, Jooste S, et al. Risk factors for HIVAIDS among youth in Cape Town, South Africa. AIDS Behav 2005;9:53-61.

9. Oyo-Ita AE, Ikpeme BM, Etokidem AJ, et al. Knowledge of HIV/AIDS among secondary school adolescents in Calabar-Nigeria. Ann Afr Med 2005;4:2-6.

10. Alene GD, Wheeler JG, Grosskurth H. Adolescent reproductive health and awareness of HIV among rural high school students, North Western Ethiopia. AIDS Care 2004;16:57-68.

11. Yerdaw M, Nedi T, Enquoselassie F. Assessment of awareness of HIV/AIDS among selected target groups in and around Addis Ababa, Ethiopia. Afr J Reprod Health 2002;6:30-8.

12. Wagbatsoma VA, Okojie OH. Knowledge of HIV/AIDS and sexual practices among adolescents in Benin City, Nigeria. Afr J Reprod Health 2006;10:76-83.

13. Negash,Y, Gebre B, Benti D, Bejiga M. A community based study on knowledge, attitude and practice (KAP) on HIV/AIDS in Gambella town, Western Ethiopia. Ethiop J Health Dev 2003;17:205-13.

14. Ministry of Health, Namibia. Home-based care handbook on HIV/AIDS: Windhoek, Namibia, 2001.

15. Red Cross. Antiretroviral therapy: Training curriculum for community counselors. Red Cross Namibia, 2001.

16. USAID. Strengthening Care and Support, Services in the Era of Treatment. Symposium Report, Johannesburg, South Africa, USAID, 2005. Available from: http://www.popcouncil.org/pdfs/horizons/s 
acssymp.pdf. (Accessed 10 May 2007).

17. Amadhila L. Ministry of Health and Social Services 2004/05. Financial Year Motivation for Budget Vote 13: Windhoek, Namibia, 2004.

18. UNAIDS. The district response initiative on HIV/AIDS - Action research study report, Pallisa district, Uganda AIDS Commission, 2003. Available from: http://www.aidsuganda.org/pdf/Pallisa_DR I_AR_Report.pdf. (Accessed 11 August 2007).
19. Ministry of Health, Ethiopia. Guideline for implementation of antiretroviral therapy in Ethiopia, Ministry of Health: Addis Ababa, Ethiopia, 2005. Available at: http://www.etharc.org/arvinfo/ethARTguid e.pdf. (Accessed 10 August 2007). 